\title{
The Role of University in Industrial Ecosystem Construction: Government - Industry Intermediary and Interdisciplinary Knowledge Fusionist
}

\author{
Li HUANG ${ }^{1,2, a}$, Sheng-hua XU ${ }^{1, b}$ \\ ${ }^{1}$ School of Information Technology, Jiangxi University of Finance and Economics, Nanchang \\ 330013, China \\ 2 Elementary Educational College, Jiangxi Normal University, Nanchang 330027, China \\ azghuangli@126.com, ${ }^{b}$ jxcdxsh@foxmail.com
}

\begin{abstract}
Keywords: university; industrial ecosystem; industrial ecosystem construction; role; government industry intermediary; interdisciplinary knowledge fusionist

Abstract. Based on the analysis of difficulties in industrial ecosystem construction, and the advantages of university to conquer the difficulties, this paper proposes the role theory framework of university in industrial ecosystem construction. The theory framework considers that giving full play to university service mission for economic and social development is an important way to solve the difficulties and university serves as government - industry intermediary role and interdisciplinary knowledge fusionist role to accomplish the mission. And finally, it puts forward the corresponding suggestions to promote industrial ecosystem construction.
\end{abstract}

\section{Introduction}

Since twentieth Century, the rapid growth of the world economy has created an unprecedented wealth. But the extensive utilization of resources and serious environmental pollution make people aware that the traditional economic activities, the one-sided pursuit of economic benefits, also brought about resource depletion and environmental degradation, seriously affecting the sustainable development of economy society. Therefore, the construction of ecological civilization and ecological economics is the objective need and inevitable choice to overcome the bottleneck of resources and environment and realize the sustainable development of economy.

Industrial ecosystem is a simulation of natural ecosystem. It is a collection of enterprises with symbiotic relationship and related organizations, in which more than two industries are linked up by the waste and byproducts to achieve the goal of eco economic efficiency[1,2]. In this concept, eco economic efficiency refers to three purposes of economy, resources and ecological environment. That is to say, not only competitive prices of products or services should be provided but also resources consumption and impact on environment should be reduced to capacity of the earth. Symbiotic relationship refers to utilize the waste or byproducts of the upper reaches in an industrial chain as the nutrients or raw materials of the downstream industry. The differences between industrial ecosystem and general industrial system mainly lie in three aspects. First of all, the former is based on industry ecology theory, while the latter is based on industry theory. Secondly, enterprises in the former always belong to different industries yet enterprises in the latter are normally of the same industry. Finally, material flows between enterprises in the former are always waste or byproduct, and those in the latter are often products[3]. Industrial ecosystem construction means the building, transformation and stable operation of the industrial ecosystem, which is an important way to realize the sustainable development strategy. In recent years, many industrial ecosystems were constructed by industry spontaneous activity or government guidance, such as Kalundborg eco industrial park, Fairfield eco industrial park, Burnside eco industrial park, Guangxi Guigang eco industrial park.

The current literatures on the main body of industrial ecosystem construction mainly highlight the role and function of the industry (enterprises) or the government as the initiator and leader[4,5,6,7,8]. However, because of the public goods attribute of resources and environment, and information asymmetry between cross-industry enterprises, the industrial ecological systems by 
enterprise spontaneous or government guidance have much instability[9,10]. In practice, the paralysis of "matchmaker" symbiosis projects by government guidance and local waste exchange network failure always resulted from the lack of government-industry communication and cross-industry integration obstacles, so that the waste utilization of scale economy, scope economy and embeddedness are not fully considered[11,12].

Many literatures have put forward that an active participation of the university has an important role in industrial ecosystem construction based on stakeholder theory or practice research $[4,13,14]$. But many problems are lack of in-depth analysis and theoretical induction, such as what advantages does the university have in industrial ecosystem construction? What is its role? How does it play the role? Based on the analysis of difficulties in industrial ecosystem construction, and the advantages of university to conquer the difficulties, this paper proposes the role theory framework of university in industrial ecosystem construction. The theory framework considers that giving full play to university service mission for economic and social development is an important way to solve the difficulties and university serves as government - industry intermediary role and interdisciplinary knowledge fusionist role to accomplish the mission. And finally, it puts forward the corresponding suggestions to promote industrial ecosystem construction.

\section{The Analysis of Difficulties in Industrial Ecosystem Construction}

(1) It is a difficulty that how to promote the close enterprises-governments collaboration and how to communicate the actual status of the industrial ecosystem construction process with the guidance of the government's ecological policy.

The public goods attribute of resources and environment causes little linkage desire based on the waste and byproducts in industrial ecosystem. Therefore, industrial ecosystem construction is not only an enterprise behavior, but also a government behavior[15]. The motivation of the formation can be summarized into two aspects. First, the internal motivation of development of the enterprise itself, that is , the pursuit of economic and social benefits which is ecologically symbiotic. For example, the waste or byproducts of the upper reach enterprise in the industrial ecosystem can be the nutrients or raw materials of the downstream enterprise, reducing the costs of pollution control of the upper reach enterprises and the costs of raw material of downstream enterprises. Second, the external motivation, such as incentives and constraints from policies, laws, technology, social supervision and so forth[16]. In practice, the paralysis of "matchmaker" symbiosis projects by government guidance always resulted from the lack of government-industry communication, so that the waste utilization of scale economy, scope economy and embeddedness are not fully considered[11,12]. Therefore, It is a difficulty that how to promote the close enterprises-governments collaboration and how to communicate the actual status of the industrial ecosystem construction process with the guidance of the government's ecological policy.

(2)It is a difficulty that how to promote the integration of material, capital, knowledge and management between cross-industry enterprises based on waste and byproducts in industrial ecosystem construction.

Industrial ecosystem is a simulation of natural ecosystem. It is a collection of enterprises with symbiotic relationship and related organizations, in which more than two industries are linked up by the waste and byproducts[1,2]. The differences between industrial ecosystem and general industrial system mainly lie in three aspects. First of all, the former is based on industry ecology theory, while the latter is based on industry theory. Secondly, enterprises in the former always belong to different industries yet enterprises in the latter are normally of the same industry. Finally, material flows between enterprises in the former are always waste or byproduct, and those in the latter are often products[3]. That is to say, the linkage based on waste and byproducts in industrial ecosystem construction are often between cross-industry enterprises, whose integration of material, capital, knowledge and management is more difficult and complex. Thus, it is a difficulty that how to promote 
the integration of material, capital, knowledge and management between cross-industry enterprises based on waste and byproducts in industrial ecosystem construction.

\section{The Analysis of the University's Advantages to Conquer the Difficulties}

(1)The legitimate basis of the university to conquer the difficulties in industrial ecosystem construction: the expansion of university mission, serving for the economic and social development

The university was first founded in Europe in the 12th century primarily with the object of teaching [17]. Later came two university revolutions. The first university revolution took place in the middle of the 19th century, which made the mission of the university change from the single object of teaching to a parallel teaching and research. The second university revolution took place in the middle of the 20th century, which made the mission of the university evolve from teaching and research to serve the economic and social development[18].

Through two revolutions the university expanded its mission, from the initial storage and dissemination of knowledge to the research and production of knowledge, and then to the use of knowledge in a variety of ways. Throughout the evolutionary process, new missions always feed back into and advance past missions and legitimize new tasks through the way that new tasks promote the completion of old tasks[19].

(2)The university's advantages to conquer the difficulties

University is a social organization that implementing high education [20]. Based on the general quality perspective, the characteristics that can distinguish the university from other institutions are "advanced nature, professional nature, broad nature, transcendent nature, public rationality, and duality of subject and object". Advanced nature means that the university is the institution of higher learning, and it is the foundation of rationality and legitimacy of the university. Professional nature refers to that the university is a loosely coupled organization composed of many majors and disciplines. Broad nature embodies in the universities' composition of majors, categories of disciplines and course, academic prosperity, richness of cultural and ideological content and so on. Transcendent nature refers to the fact that the lifespan of the university is longer than any form of governments, traditions, legal changes and scientific thinking, because it meets people's eternal needs. Public rationality refers to the process and the faith that people use basic common sense, logic, and practice to confirm or test the authenticity. The duality of subject and object means that the university is both the object existence and the subject existence [21,22].

Therefore, the university's mission of serving economic and social development in the industrial ecosystem construction has the following advantages:

First of all, advanced nature, professional nature, transcendent nature, and public rationality of the university make the university's own social identity dual. That is to say, for the industry, it has a certain degree of government credibility and academic authority, and for the government, it has the capacity to theorize the industrial practice. Therefore, the university is the best government - industry intermediary and bridge. It can effectively promote the close collaboration between enterprises and governments, and communicate the actual status of the industrial ecosystem construction process with the guidance of the government's ecological policy.

Secondly, advanced nature, professional nature, and broad nature make the university, especially the comprehensive university, become the concentration of many talents and discipline knowledge such as literature, science, engineering, economy and management, and a place with conditions and atmosphere for communication and cross application of interdisciplinary knowledge. Therefore, the university is the best technical and managerial fusionist between different industries and enterprises in the industrial ecosystem construction. It can promote the integration of materials, capital, knowledge and management between different industries and enterprises based on wastes and byproducts. 


\section{The Role Theory Framework of University in Industrial Ecosystem Construction}

According to the analysis of difficulties in industrial ecosystem construction, and the advantages of university to conquer the difficulties, this paper proposes the role theory framework of university in industrial ecosystem construction as shown in figure 1 . The theory framework considers that giving full play to university service mission for economic and social development is an important way to solve the difficulties and university serves as government - industry intermediary role and interdisciplinary knowledge fusionist role to accomplish the mission. In it, government - industry intermediary role means the university can effectively promote the close collaboration between enterprises and governments, and communicate the actual status of the industrial ecosystem construction process with the guidance of the government's ecological policy. Interdisciplinary knowledge fusionist role refers to that the university can promote, coordinate and supervise the integration of materials, capital, knowledge and management between different industries and enterprises based on wastes and byproducts.

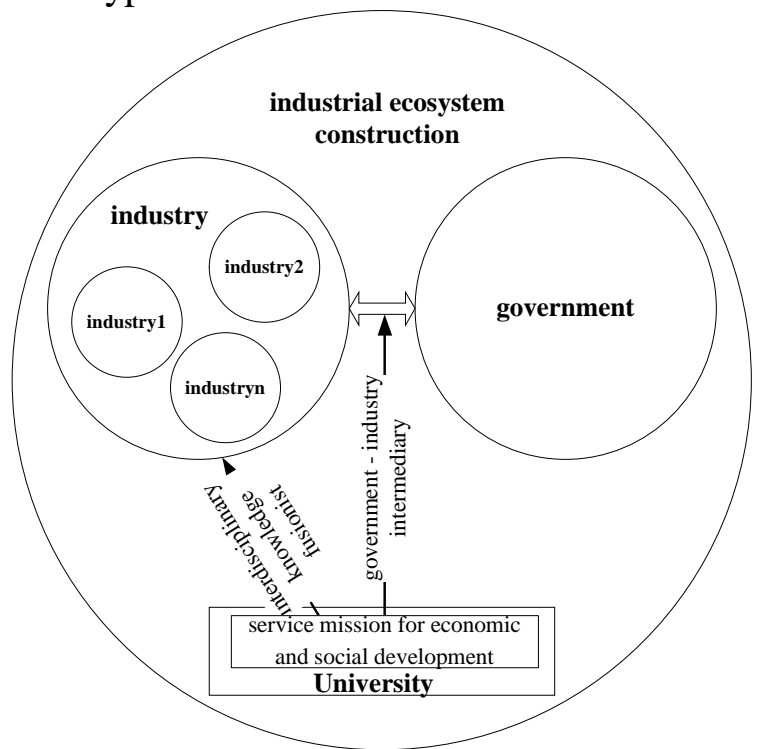

Fig1. the role of university in industrial ecosystem construction

\section{Conclusions and Suggestions}

The research of this paper has provided important theory and experience for industrial ecosystem construction. Based on the research of this paper, the following suggestions are put forward for industrial ecosystem construction:

(1) To fully understand and attach importance to the role of the university in industrial ecosystem construction. In the industrial ecosystem, because of the public goods attribute of resources and environment, and information asymmetry between cross-industry enterprises, the industrial ecosystems by enterprise spontaneous or government guidance have much instability[9-10]. The university is an important way to solve the difficulties.

(2) To fully understand and attach importance to the role of the university in industrial ecosystem construction as "government - industry intermediary role and interdisciplinary knowledge fusionist". Due to its own social identity, for the industry, the university has a certain degree of government credibility and academic authority, and for the government, it has the capacity to theorize the industrial practice. Therefore, the university is the best Government - Industry Intermediary and bridge. It can effectively promote the close collaboration between enterprises and governments, and communicate the actual status of the industrial ecosystem construction process with the guidance of the government's ecological policy. The university boasts conditions and atmosphere for communication and cross application of interdisciplinary knowledge and can promote the integration of materials, capital, knowledge and management between different industries and enterprises based 
on wastes and byproducts, which make the university the interdisciplinary knowledge fusionist in the industrial ecosystem construction.

(3) To create conditions and establish incentive system from different angles and perspectives in order to give full play to the role of universities in industrial ecosystem construction. For example, strengthening the construction of the communication platform between university, government and industry; strengthening the research orientation of ecological economic construction, tilting in the horizontal and vertical project funds, improving the patent system and stimulating the enthusiasm of university in eco-economic research and construction.

\section{Acknowledgements}

This work was financially supported by National Natural Science Foundation of China (71261009), and National Natural Science Foundation of China (71561010).

\section{References}

[1] R.A. Frosch, N.E Gallopoulos: Scientific American, Vol. 261(1989), p.94-102.

[2] Y. Fang, R.P. Cote and R. Qin: Journal of environmental management, Vol. 83(2007),p. 315-328.

[3] L. Huang, S.H. Xu: Research on library science, Vol. 13(2015), p. 2-9.

[4] R.R. Heeres, W.J.V. Vermeulen and F.B. Walle: Journal of Cleaner Production, Vol. 12(2004), p.985-995.

[5] X.L Wang, C.F. Li: Systems Engineering,Vol. 24(2006),p.9-12.

[6] Y.T. Han, F.Q. Li: Environment Protection,Vol.2(2009), p.30-32.

[7] Y.H. Guo: Science \& Technology Progress and Policy,Vol.31(2014),p.63-69.

[8] P.Y. Zhu:China Soft Science,Vol.1(2015),p.14-19.

[9] G. Zilahy:Journal of Cleaner Production,Vol.12(2004), p.311-319.

[10] C.Y. Wu, H. Deng and N. Duan: China Population, Resources and Environment, Vol.15(2005),p.20-25.

[11] L.Shi:Acta Ecologica Sinica, Vol.28(2008),p. 3356-3364.

[12] M.F.Liu, W.C.Wei:Science and Technology Management Research,Vol.8(2005),p. 121-125.

[13] C.E.Grip, S.Erik, G.Rikard, et al. : submitted to the 4th International Seminar on Society \& Materials(2010).

[14] K.S.Long, Y.R.Wang, Y.L.Zhao and L.G.Chen: China Population, Resources and Environment,Vol.25(2015),p. 43-49.

[15] Y.H.Guo: Forum on Science and Technology in China,Vol.10(2013),p.138-145.

[16] Y.Zhou, C.B.Yin and J.C. Zhang: Ecological Economy,Vol.2(2012),p.36-40,51.

[17] H.Rashdall, in: The Universities of Europe in the Middle Ages, Oxford University Press, Oxford (1896), in press.

[18] C.Y.Zhou: Studies in Dialectics of Nature,Vol.22(2006),p.75-77,82.

[19] H.Etzkowitz: Studies in Science of Science, Vol.27(2009),p.481-488.

[20] Y.F.Sui:Journal of Higher Education,Vol.4(2000),p. 49-52.

[21] F.Wang:Higher education of sciences,Vol.4(2012),p.26-30. 
[22] Y.N.Zhu:Science Research Management,Vol.1(2015),p.200-204. 